\title{
An experimental study on the dimensional accuracy of holes made by abrasive waterjet machining of Hardox steels
}

\author{
Alexandru Catalin Filip ${ }^{1, *}$, Laurentiu Aurel Mihail ${ }^{1}$ and Mircea Anton Vasiloni ${ }^{1}$ \\ ${ }^{1}$ Transilvania University of Brasov, Department of Manufacturing Engineering, Mihai Viteazul No.5, \\ Romania
}

\begin{abstract}
The manufacturing process of special steels like Hardox is usually difficult. Abrasive waterjet cutting (AWJ) is one of the machining processes which can be used in this case, with good results, as proved in previous research of the authors. This paper presents an experimental study on the influence of the AWJ main process parameters to the dimensional accuracy of holes manufactured in Hardox steels. The experiments were conducted using a $\mathrm{L}_{8}\left(2^{4}\right)$ fractional factorial design matrix considering four parameters: the traverse speed, the part thickness, the hole dimension and the material type. Based on the measurement of the dimensions of the holes, the influence of those parameters was revealed and analyzed. The manufacturing time was also registered, as this parameter directly influences the production cost. Further research aims developing a mathematical model which will be a useful tool in workshop process planning.
\end{abstract}

\section{Introduction}

Heavy industries like mining or the construction of roads use equipments with special requirements such as a strong wear resistance and a high tenacity. A range of materials which meet those requirements is the Hardox steel alloys family [1, 2]. Such steels can be processed by traditional mechanical cutting processes like milling or drilling [2] and also by non-traditional ones like thermal cutting or AWJ. One main advantage of AWJ is the absence of modifications of the material properties during the manufacturing process. In all other cases, there is a so-called HAZ - Heat Affected Zone, which for Hardox steels means a decrease of its initial hardness.

Abrasive waterjet machining is a flexible manufacturing process, considered to be one the most developing methods in the last decades [3, 4]. It is based [5], Figure 1a, on using a stream of water (1) at high pressures, above 3000 bar, guided through a small calibrated orifice (2) and mixed with fine abrasive particles (5) in a mixing chamber (3). The abrasive stream is then sent through a nozzle (4), towards the surface of the material. The part (6) is fixed above a matrix of slats (7) which allows the water, the abrasive and the material removed to be collected into the tank below.

\footnotetext{
*Corresponding author: filipal@unitbv.ro
} 


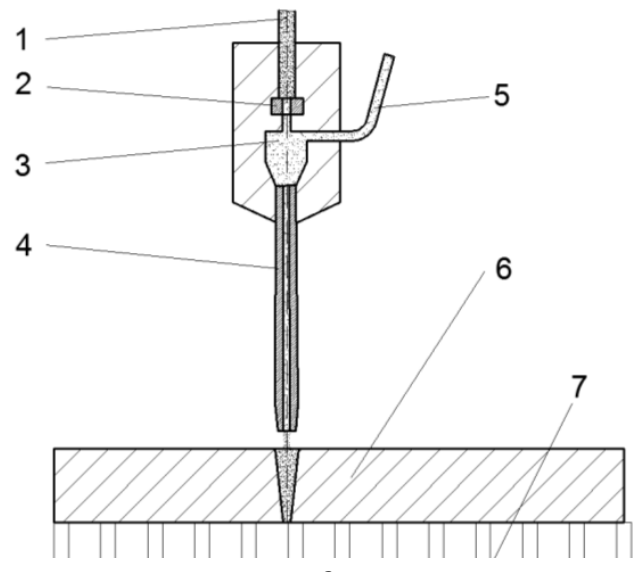

a.

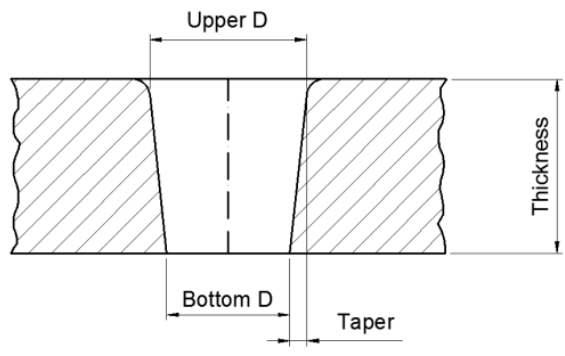

b.

Fig. 1. a. Principle of abrasive waterjet cutting; b. Taper kerf formation.

The high speed of the abrasive jet creates enough force able to cut the material of the part. The cutting head is moved by a CNC controller, using dedicated software.

The main advantages of the AWJ method are: the capacity to cut almost any type of material, no thermal influence, easy and fast setup and a high flexibility. The process is also environmentally friendly as the "tools" - water and abrasive particles - are fully recyclable.

The quality of the part is defined by the geometrical and dimensional accuracy and the roughness of the surface. The typical shape of the slot is presented in Figure 1b. The transversal section of the cut is not rectangular, but a tapered one, usually called kerf. Normally, the dimension of the slot is greater on the AWJ entrance surface (the upper one) than the exit surface (the bottom one). The latest modern equipment for AWJ manages to compensate the kerf formation by using the machine dynamics. But if the machine does not have kerf compensation options, this phenomenon must be controlled by other process parameters.

The AWJ process is complex. There is a larger number of parameters which have an influence on the quality and cost of the process [5]. In the last decade there were published several research studies on AWJ, focusing mainly on the surface roughness, the kerf formation and the influence of the traverse speed on those parameters [6-13]. But each research analysed one type of material and the results have the validity for that type of material.

Since AWJ is not a common manufacturing process, today there is a lack of technological data for many materials when someone wants to process them by AWJ. Each abrasive waterjet commercial machine uses its own cutting model and it has a materials database from which the operator can select the one needed. If the material is not in that database, there will have to be selected a similar one, but the cutting model will not be accurate and the results may not be as expected.

In the case of Hardox steels family there is a very few data for the abrasive machining method. The authors of this paper have made some previous studies on the AWJ of this materials [14] aiming to reveal the machinability of Hardox steels by abrasive waterjet machining. Some other research papers [11,13] proposed regression models of the dependence between the traverse speed, the water pressure, the abrasive flow rate and the roughness of the surface which is obtained after the process.

The present research continues the previous studies, analyzing the influence of the main process parameters on the dimensional accuracy of circular holes, manufactured by AWJ on 
Hardox steels parts. The kerf level was investigated and how the process parameters influence its values.

\section{Setup of experiments and measurement of the parts}

The experiments were realized on two types of Hardox steel, Hardox 450 and Hardox 500, which are the most commercially used grades [2]. Their mechanical properties [1-2] are according to Table 1.

Table 1. Mechanical properties of the steels type Hardox.

\begin{tabular}{|c|c|c|c|}
\hline Material Grade & $\begin{array}{c}\text { Hardness HBW } \\
\text { Brinell }\end{array}$ & $\begin{array}{c}\text { Yield Strength } \\
{\left[\mathbf{N} / \mathbf{m m}^{\mathbf{2}}\right]}\end{array}$ & $\begin{array}{c}\text { Tensile Strength } \\
{\left[\mathbf{N} / \mathbf{m m}^{2} \mathbf{]}\right.}\end{array}$ \\
\hline Hardox 450 & $425 \ldots 475$ & 1200 & 1400 \\
\hline Hardox 500 & $470-530$ & 1300 & 1550 \\
\hline
\end{tabular}

The tests were performed in the laboratory of Advanced Manufacturing Technologies, on a waterjet machine type Maxiem, having a $20 \mathrm{HP}$ pump and a maximum water pressure of 3500 bar. The dynamics of the machine does not have the possibility of automatic tilting, to compensate the effect of taper surface. The abrasive feeding system is a regular one, with constant feed rate, which was carefully measured before the experiments.

The main technological parameters of influence on the process of AWJ which are considered by the comprehensive researches until present day [3-13] are: the water pressure, the traverse speed, the abrasive flow rate and the distance between the nozzle and the surface of the material to be cut, usually called standoff distance. The water pressure directly influences the process productivity and costs and almost all researches agree that it is better to use the maximum value given by the equipment. Because the machine used for experiments has a unique flow rate of the abrasive, there was used this default rate during the tests. For this research, the standoff distance was also considered constant. All the values of the constant parameters are given in Table 2. Usually, the values of these parameters are typical for many industrial applications of AWJ [4].

Table 2.Values of the constant parameters used during the tests.

\begin{tabular}{|c|c|c|c|c|c|}
\hline $\begin{array}{c}\text { Water } \\
\text { pressure } \\
{[\mathbf{b a r}]}\end{array}$ & $\begin{array}{c}\text { Abrasive } \\
\text { flow rate } \\
{[\mathbf{g} / \mathbf{m i n}]}\end{array}$ & $\begin{array}{c}\text { Abrasive } \\
\text { type }\end{array}$ & $\begin{array}{c}\text { Standoff } \\
\text { distance } \\
{[\mathbf{m m}]}\end{array}$ & $\begin{array}{c}\text { Jewel orifice } \\
\text { diameter }[\mathbf{m m}]\end{array}$ & $\begin{array}{c}\text { Nozzle orifice } \\
\text { diameter [mm] }\end{array}$ \\
\hline 3500 & 370 & $\begin{array}{c}\text { garnet } 80 \\
\text { mesh }\end{array}$ & 1.5 & 0.279 & 0.838 \\
\hline
\end{tabular}

There was designed a four parameter experiment, considering the material type, the traverse speed, the part thickness and the diameter of the hole. The levels of these parameters are presented in Table 3. The levels of the traverse speed were chosen based on previous experiments done by others [6-13] and by the authors [14] for the type of material which was tested. The levels for the other parameters were chosen based on some practical considerations about the use of Hardox steels in the real workshop of the company which is partner in this research project.

Based on the levels of the parameters from Table 3, a $\mathrm{L}_{8}\left(2^{4}\right)$ fractional factorial plan of experiments was designed. The matrix of the experiments is according to Table 4 which contains also the cutting time (as response variable), calculated by the machine software. As seen in Table 4 the experiment contains 8 trials for the 4 factors, each one variated at 2 levels. Each test was repeated five times for obtaining a relatively enough high statistical confidence on the data. 
Table 3. Levels of the variable parameters chosen for the experiment.

\begin{tabular}{|c|l|c|c|c|}
\hline No & Process Parameter & Units & Level 1 & Level 2 \\
\hline 1 & Material type & n.a. & Hardox 450 & Hardox 500 \\
\hline 2 & Traverse speed & $\mathrm{mm} / \mathrm{min}$ & 30 & 60 \\
\hline 3 & Material thickness & $\mathrm{mm}$ & 12 & 20 \\
\hline 4 & Diameter of the hole & $\mathrm{mm}$ & 20 & 30 \\
\hline
\end{tabular}

Table 4. The matrix of the experiment.

\begin{tabular}{|c|c|c|c|c|c|}
\hline $\begin{array}{c}\text { Trial } \\
\text { Nr. }\end{array}$ & $\begin{array}{c}\text { Material } \\
\text { type }\end{array}$ & $\begin{array}{c}\text { Traverse } \\
\text { speed } \\
{[\mathbf{m m} / \mathbf{m i n}]}\end{array}$ & $\begin{array}{c}\text { Part thickness } \\
{[\mathbf{m m}]}\end{array}$ & $\begin{array}{c}\text { Hole diameter } \\
{[\mathbf{m m}]}\end{array}$ & $\begin{array}{c}\text { Cutting Time } \\
{[\mathbf{m i n}]}\end{array}$ \\
\hline 1 & 1 & 30 & 12 & 20 & 3.14 \\
\hline 2 & 1 & 30 & 20 & 30 & 5.26 \\
\hline 3 & 1 & 60 & 12 & 30 & 2.42 \\
\hline 4 & 1 & 60 & 20 & 20 & 1.97 \\
\hline 5 & 2 & 30 & 12 & 30 & 4.78 \\
\hline 6 & 2 & 30 & 20 & 20 & 3.67 \\
\hline 7 & 2 & 60 & 12 & 20 & 2.44 \\
\hline 8 & 2 & 60 & 20 & 30 & 2.77 \\
\hline
\end{tabular}

The dimensional accuracy and the taper effect were analyzed by measuring the dimension of each hole, with an optical digital profilometer, Mitutoyo Quick Image Vision measuring system (Figure 2). The dimension was measured on the both sides of the part, named the upper (entrance of the abrasive jet, "IN diameter") and the bottom (exit of the abrasive jet, "OUT diameter").

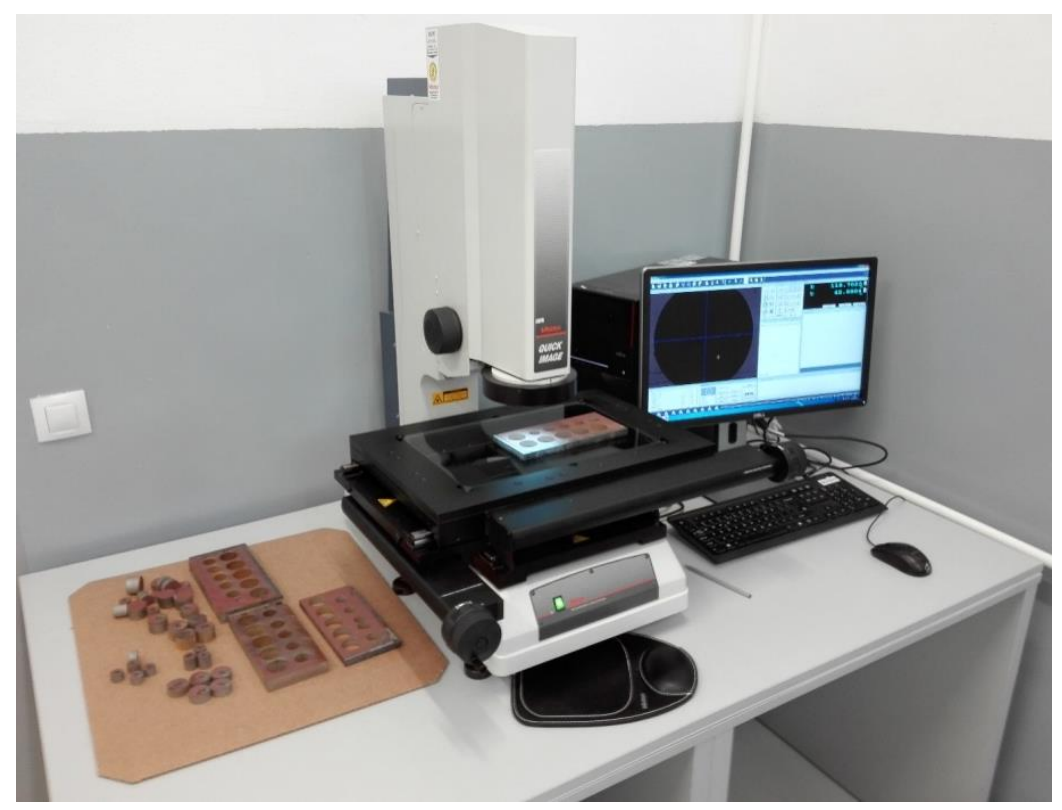

Fig. 2. The measuring setup from Mitutoyo. 
In Figure 3 there are presented two sets of experiments, for a certain material type, for the two levels of thickness chosen.
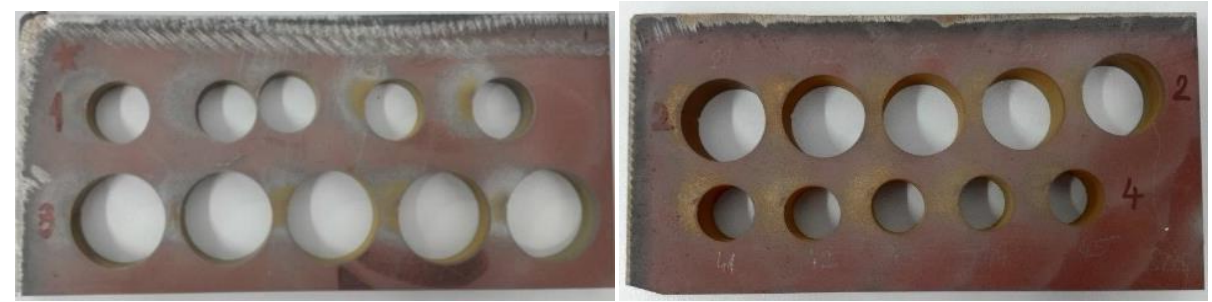

Fig. 3. Set of holes machined during the experiments, for Hardox 450 steel. Left - thickness of 12 $\mathrm{mm}$. Right - thickness of $20 \mathrm{~mm}$.

\section{Analysis of the results}

The AWJ process is a complex one. During the present research, the main aim was to point out the influence of four parameters on the dimensional accuracy of circular holes machined by AWJ in Hardox steels. While using two levels of variation for each of the four parameters (Table 3), the other process parameters were considered constant at the levels indicated in Table 2. Based on these facts, the performance diagram of the experiment is illustrated in Figure 4.

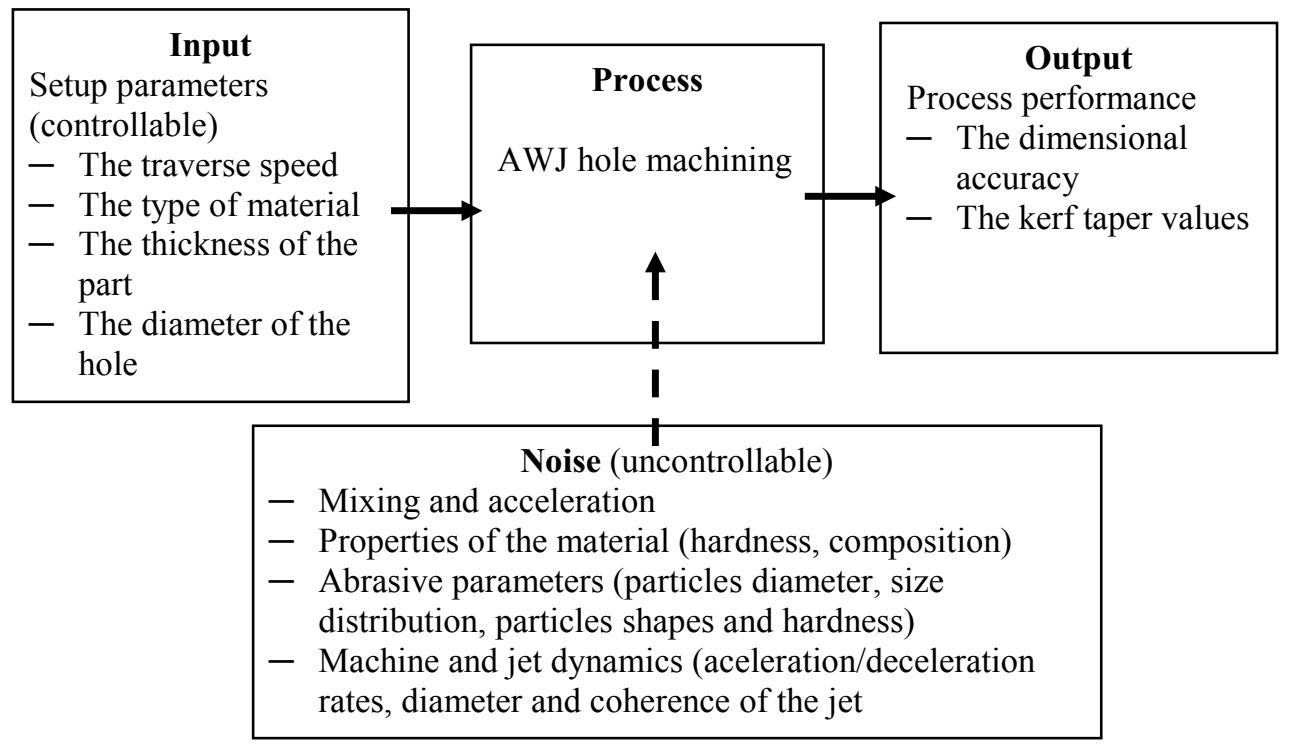

Fig. 4. The P Diagram for the studied AWJ process.

For the statistical analysis, there were calculated the values of the difference between the upper and the bottom value of the hole diameter:

$$
\text { Diff=IN_diam-OUT_diam. }
$$

The values of the difference calculated with the Equation (1) are, in fact, the double of the kerf (Figure 1b). The arithmetic mean of values of the hole's diameter measured after the experiments and their deviations from the nominal value are presented in Table 5. 
Table 5. Experiment mean values of the dimensional accuracy.

\begin{tabular}{|c|c|c|c|c|c|}
\hline $\begin{array}{c}\text { Trial } \\
\text { No }\end{array}$ & $\begin{array}{c}\text { IN Diameter } \\
{[\mathbf{m m}]}\end{array}$ & $\begin{array}{c}\text { OUT Diameter } \\
{[\mathbf{m m}]}\end{array}$ & $\begin{array}{c}\text { Difference } \\
{[\mathbf{m m}]}\end{array}$ & $\begin{array}{c}\text { IN Deviation } \\
\text { from nominal } \\
{[\mathbf{m m}]}\end{array}$ & $\begin{array}{c}\text { OUT Deviation } \\
\text { from nominal } \\
{[\mathbf{m m}]}\end{array}$ \\
\hline $\mathbf{1}$ & 20.315 & 20.086 & 0.229 & 0.315 & 0.086 \\
\hline $\mathbf{2}$ & 30.375 & 30.114 & 0.261 & 0.375 & 0.114 \\
\hline $\mathbf{3}$ & 30.261 & 29.981 & 0.280 & 0.261 & -0.019 \\
\hline $\mathbf{4}$ & 20.338 & 20.086 & 0.252 & 0.338 & 0.086 \\
\hline $\mathbf{5}$ & 30.318 & 30.082 & 0.236 & 0.318 & 0.082 \\
\hline $\mathbf{6}$ & 20.307 & 20.133 & 0.174 & 0.307 & 0.133 \\
\hline $\mathbf{7}$ & 20.337 & 20.008 & 0.329 & 0.337 & 0.008 \\
\hline $\mathbf{8}$ & 30.326 & 30.136 & 0.190 & 0.326 & 0.136 \\
\hline
\end{tabular}

Generally, the Taguchi method analyses with statistical tools the performance of the process for optimizing it $[15,16]$. The signal to noise ratio $(\mathrm{S} / \mathrm{N})$ is used as decision function assessing the quality characteristic (S) for robust optimisation. In this case, both of the performance parameters - the dimensional accuracy and the kerf taper values - are following the principle "the smaller is better". Thus, the objective function is defined like following:

$$
S / N=-10 \cdot \log \left(s^{2}+\bar{y}^{2}\right) .
$$

Using the mean values of the difference calculated with the Equation (1), the analysis of means (ANOM) was applied for the computed Signal to Noise indexes, considering the principle "Smaller is Better" (S/N STB). The results are presented numerically in Table 6 and, graphically, in Figure 5. According with it, the highest influence on the studied quality characteristic is given by the traverse speed, followed by the type of the material and the part thickness. The lowest influence is given by the hole diameter. The values of the ranges which suggest the relative importance of the four parameters is specified in Table 6, by the row "Delta" and, accordingly, the order of significance is given by the row "Rank".

Table 6. Response table for Signal to Noise Ratios "Smaller is better".

\begin{tabular}{|c|c|c|c|c|}
\hline Level & Type of material & Traverse speed & Part thickness & Hole diameter \\
\hline 1 & 11.22 & 12.73 & 11.40 & 11.93 \\
\hline $\mathbf{2}$ & 12.62 & 11.11 & 12.44 & 11.91 \\
\hline Delta & 1.40 & 1.62 & 1.04 & 0.02 \\
\hline Rank & 2 & 1 & 3 & 4 \\
\hline
\end{tabular}

The response table for means, on the Taguchi analysis, puts in evidence the magnitude of the studied quality characteristic, relatively at the dimensions measured. Table 7 and Figure 6 underline the impact on the studied quality deviation of the four experimental parameters. The highest influence is given by the part thickness, followed by the traverse speed. The type of material has a relatively medium influence and the hole's diameter has a very low contribution. The magnitude, expressed in millimetres, is given in Table 7 by the row "Delta".

Assuming a linear model for the response quality characteristic, the difference between the upper and the bottom diameter of the hole, Diff, Equation (1), the model will be: 
$D d=0,244025+0,011525 * M t-0,018875^{*} T s+0,024325 * P t+0,002225 * H d$.

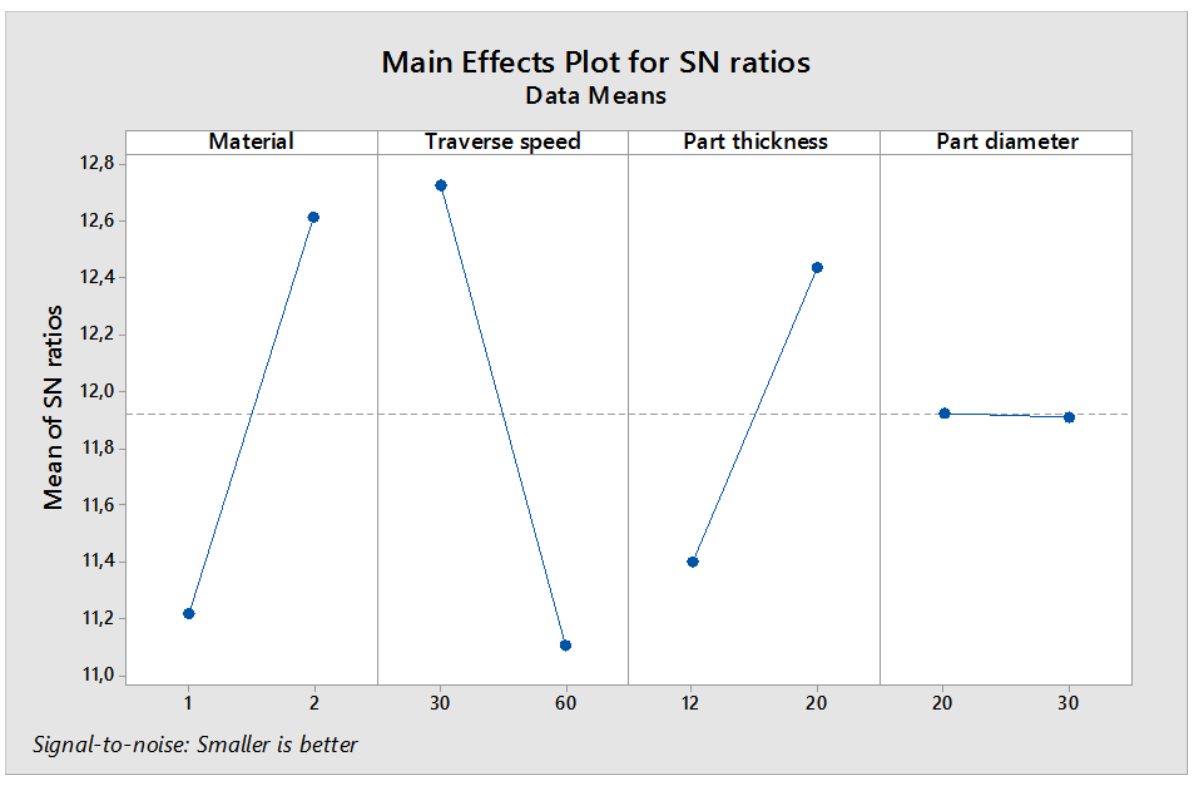

Fig. 5. Response Graph for Signal to Noise Ratios Smaller is better.

Table 7. Response table for means.

\begin{tabular}{|c|c|c|c|c|}
\hline Level & Type of material & Traverse speed & Part thickness & Hole diameter \\
\hline 1 & 0.2556 & 0.2251 & 0.2683 & 0.2463 \\
\hline $\mathbf{2}$ & 0.2325 & 0.2629 & 0.2197 & 0.2418 \\
\hline Delta & 0.0230 & 0.0378 & 0.0486 & 0.0045 \\
\hline Rank & 3 & 2 & 1 & 4 \\
\hline
\end{tabular}

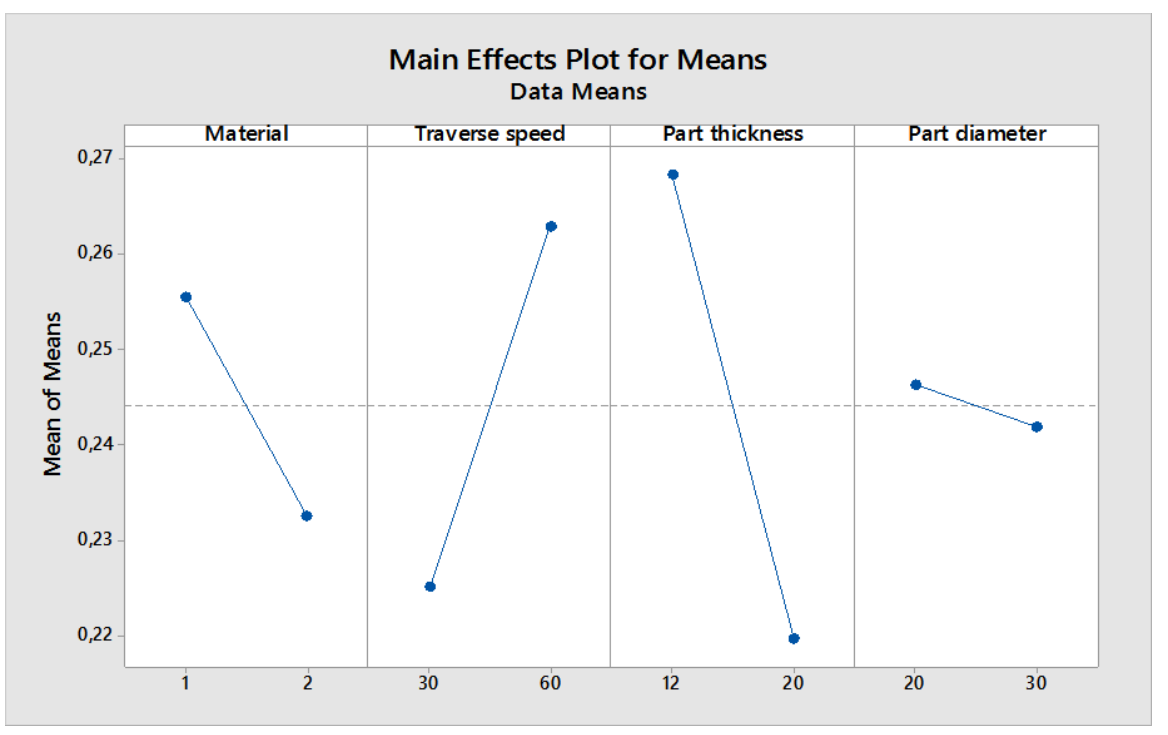

Fig. 6. Response Graph for means. 
In Equation (2), Mt is the type of material, $T s$ is the traverse speed, $P t$ is the part thickness and $H d$ is the hole diameter.

The model estimators are:

- $\mathrm{s}=0,05216$ (the squared error);

- $\mathrm{R}-\mathrm{Sq}=51,6 \%$ (the determination coefficient);

- $\mathrm{R}-\mathrm{Sq}(\operatorname{adj})=0,0 \%$ (the adjusted determination coefficient).

Those statistics put in evidence the variation of the predictors relatively at the response variable. The $\mathrm{R}-\mathrm{Sq}(\operatorname{adj})$ obtained value underlines the fact that this parameter is not relevant for the obtained mathematical model.

In Table 8 there is presented the analysis of variance (ANOVA) of means for the linear mathematical model, given by Equation (3). According with it, the statistical significance can be improved, by raising the confidence level of the data (a higher number of observations). Also, the ANOVA analysis takes into consideration the fact that for the linear model, there are made the following assumptions about the probability distribution of the responses:

- independence of observations - this is an assumption of the model that simplifies the statistical analysis;

- normality - the distributions of the residuals are normal;

- equality (or "homogeneity") of variances, called homoscedasticity — the variance of data in groups should be the same.

The ANOVA analysis presented in Table 8 shows that the error variances are very low, so the level of confidence can be considered good enough. Meanwhile, the values of $F$ and $P$ factors show that for a higher level of confidence, the number of tests should be higher.

Table 8. ANOVA for the linear mathematical model.

\begin{tabular}{|c|c|c|c|c|c|c|}
\hline Source & $\begin{array}{c}\text { Degrees of } \\
\text { Freedom }\end{array}$ & Seq SS & Adj SS & Adj MS & F & P \\
\hline $\begin{array}{c}\text { Material } \\
\text { type }\end{array}$ & 1 & 0.001063 & 0.001063 & 0.001063 & 0.39 & 0.576 \\
\hline $\begin{array}{c}\text { Traverse } \\
\text { speed }\end{array}$ & 1 & 0.002850 & 0.002850 & 0.002850 & 1.05 & 0.381 \\
\hline $\begin{array}{c}\text { Part } \\
\text { thickness }\end{array}$ & 1 & 0.004734 & 0.004734 & 0.004734 & 1.74 & 0.279 \\
\hline $\begin{array}{c}\text { Hole } \\
\text { diameter }\end{array}$ & 1 & 0.000040 & 0.000040 & 0.000040 & 0.01 & 0.912 \\
\hline $\begin{array}{c}\text { Residual } \\
\text { error }\end{array}$ & 3 & 0.008161 & 0.008161 & 0.002720 & & \\
\hline Total & 7 & 0.016847 & & & & \\
\hline
\end{tabular}

The dispersion of the data was also analysed. The data is presented in Table 9 and Figure 7. According to the values, the variability of the data is the highest for the part thickness, followed at relatively the same level by the type of material and the traverse speed. The lowest variability level is for the part diameter.

Table 9. The response table for standard deviations.

\begin{tabular}{|c|c|c|c|c|}
\hline Level & Type of material & Traverse speed & Part thickness & Hole diameter \\
\hline 1 & 0.10403 & 0.06230 & 0.04819 & 0.08320 \\
\hline $\mathbf{2}$ & 0.05793 & 0.09966 & 0.11377 & 0.07876 \\
\hline Delta & 0.04610 & 0.03736 & 0.06558 & 0.00445 \\
\hline Rank & 2 & 3 & 1 & 4 \\
\hline
\end{tabular}




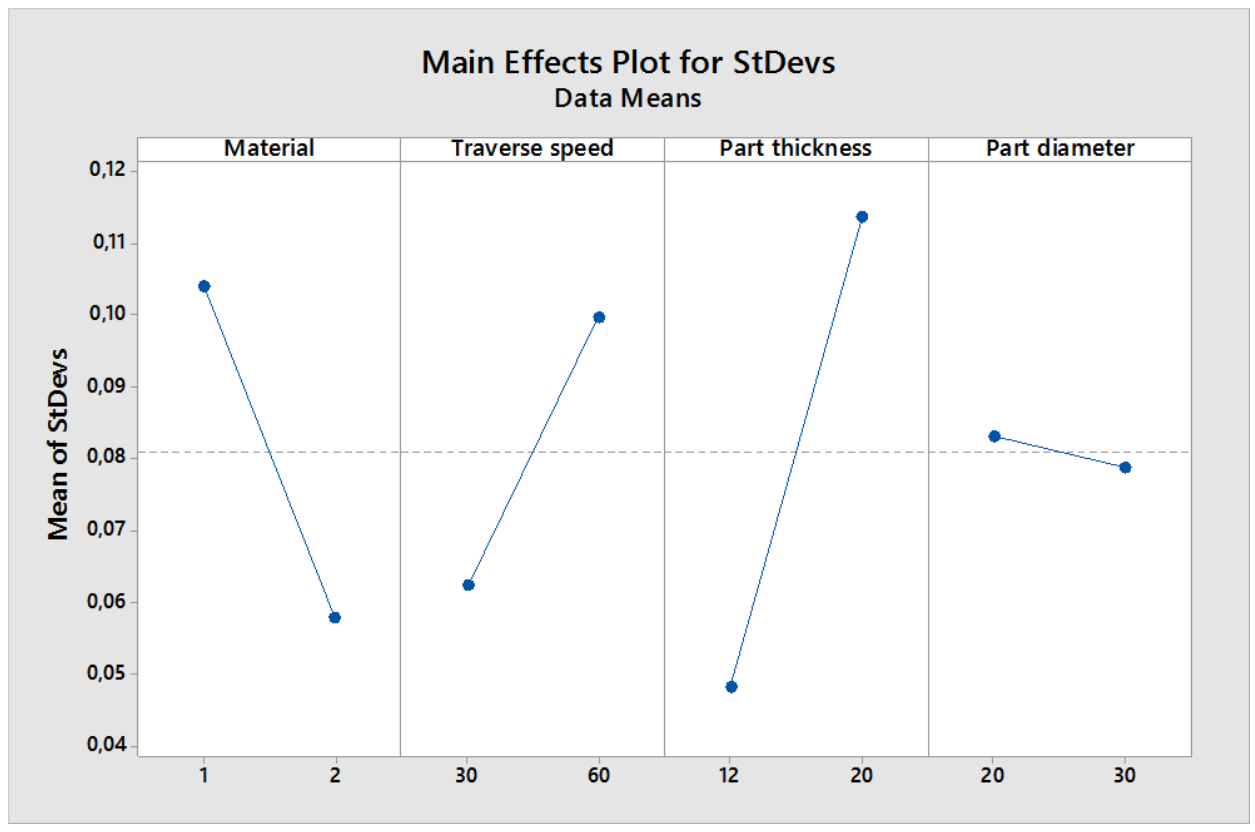

Fig. 7. Response Graph for standard deviations

\section{Conclusions}

This experimental research aimed to reveal the influence of the process parameters on the dimensional accuracy of holes machined by AWJ in Hardox steels.

An experimental plan was designed, with a four-parameter matrix, presented in Table 4. All the designed combinations were conducted, so the orthogonality of the experiment was assured. The dimensional accuracy was assessed by measuring the dimension of each hole on the two sides of the part, the upper and the bottom (Figure 1b). This allowed the evaluation of the kerf values, as this phenomenon directly affects the part geometry.

The measured data was analysed using the Taguchi method with statistical tools. The main conclusions of the research are:

- The $\mathrm{S} / \mathrm{N}$ ratios analysis (Figure 5) revealed that the traverse speed is the most important parameter of influence on the dimensional accuracy of parts. It is followed by the material type and thickness. The diameter of the hole has a very small influence. The lower the traverse speed and the higher the part thickness are, the better is the dimensional accuracy. The diagram $\mathrm{S} / \mathrm{N}$ ratios shows also that the best levels for obtaining the best performance level are level 2 for the material type (Hardox 500), a traverse speed of $30 \mathrm{~mm} / \mathrm{min}$ and a thickness of $20 \mathrm{~mm}$.

- The analysis of means (ANOM) shows that the part thickness is the most important parameter of influence, followed nearly by the traverse speed and the type of material.

- The ANOVA analysis shows that the error variances are very low, but the level of confidence must be raised by raising the number of tests.

- All of the statistical tests revealed that the hole's diameter has a very low influence on the dimensional accuracy and the type of the material has a medium influence together with the part thickness.

- The analysis of the experimental results are in accordance with other previous researches on Hardox and other materials, revealing that the traverse speed is the most significant 
parameter of influence on the part's accuracy, as well as on the part's surface quality measured by its roughness.

For a more accurate estimation of the process performance, further research will be developed, using also other types of Hardox steels to establish a mathematical model for predicting the process parameters when this type of material needs to be manufactured by abrasive waterjet cutting (AWJ).

The experiments of this research were made with the support of the project PN-III-P2-2.1-BG-20160206, ProWaterjetTech, financed by UEFISCDI. The measurements were done on the infrastructure of the "Metrology Lab Mitutoyo" from the "Institute High Tech Products for Sustainable Development: PRO-DD", lab created with the support of Mitutoyo Romania S.R.L.

\section{References}

1. H. Bugłacki, M. Smajdor, Advances In Materials Science, 4, 2 (2003)

2. Hardox steels. http://www.ssab.com/products/brands/hardox (2017)

3. R. Kovacevic, M. Hashish, R. Mohan, M. Ramulu, TJ. Kim, ES. Geskin, J Manuf Sci Eng, 119, 776-785 (1997)

4. J. Folkes, J Mater Process Tech, 209, 6181-6189 (2009)

5. A.W.Momber, R.Kovacevic, Principles of Abrasive Waterjet Machining. Springer London Limited (1998)

6. YW. Seo, M. Ramulu, D. Kim, Proc Inst Mech Eng B, 217 (12) 1709 (2003)

7. A. Akkurt, M K. Kulekci, U. Seker, F. Ercan, J Mater Process Technol 147 (3) 389 (2004)

8. D. Krajcarz, Procedia Engineering, 69 838-843 (2014)

9. J. Kechagias, G. Petropoulos, N.Vaxevanidis, Int J Adv Manuf Technol 62 635-643 (2012)

10. L.M. Hlavac, I.M. Hlavacova, V. Geryk, S. Plancar, Int J Adv Manuf Technol 77 1811-1818 (2015)

11. L.M. Hlavac, S.Spadlo, D. Krajcarz, I.M.Hlavacova, Proceedings of the 24th International Conference on Metallurgy and Materials Metal, Brno (2015)

12. H. Li, J. Wang, Int J Adv Manuf Technol, 81 361-369 (2015)

13. M. Zohoor, S.H. Nourian, M. Salehi, Int J Advanced Design and Manufacturing Technology, 5 (2012)

14. A.C. Filip, M. Vasiloni, L.A. Mihail, MATEC Web of Conferences, 94 (2017)

15. G. Taguchi, S. Chowdhury, Y. Wu, Taguchi's Quality Engineering Handbook. John Wiley \& Sons and ASI (2004)

16. Minitab release 17 statistical software, Minitab Inc., USA 